\title{
THE USE OF RADIO-FREQUENCY ABLATION IN THE TREATMENT OF MALIGNANT TUMORS OF LUNGS AND PLEURA
}

\author{
Vladisav Severgin \\ Department of reconstructive and rehabilitative medicine \\ Odessa National Medical University \\ 2 Valihovsky per., Odessa, Ukraine, 65082 \\ Gedeon241@rambler.ru \\ Sergei Prohoda \\ Odessa oncologic hospital \\ 26 Nejdanova str., Odessa, Ukraine, 65056 \\ Aleksey Prohoda \\ Odessa National Medical University \\ 2 Valihovsky per., Odessa, Ukraine, 65082
}

\begin{abstract}
Aim of the work. Analysis of the possibilities of the different methods of RFA of lung and pleura tumors.

Material and methods. There were considered the different methods of radio-frequency ablations using FOTEK-150 apparatus in 186 patients with the malignant tumors of lungs and pleura.

Results. In the result of use of the different methods of radio-frequency ablation the direct positive effect was attained in $91 \%$ of observations. The complications were observed in $9 \%$ of patients. This method must be used for patients with the malignant tumors of lungs and pleura when the radical surgical treatment is impossible.

Conclusions. The radio-frequency ablation can be used as a palliative method of treatment of the malignant tumors of lungs and pleura.
\end{abstract}

Keywords: radio-frequency ablation, lung cancer, metastatic pleurisy.

\section{Introduction}

The method of radio-frequency ablation (RFA) is based on the effect of effervescence of intracellular liquid with destruction of the tumor cells using the radio-frequency airwaves delivered to the tumor with the help of special electrode $[1-2,5-6,10]$. Radio-frequency ablation is widely used in the treatment of malignant tumors of liver. The publications about the use of this method at the primary and metastatic lung cancer appeared last years. Theoretically it can be effectively used for RFA because the ambient air allows concentrate the energy of RF-eradiation directly in the node preventing the lesion of the large volume of lung parenchyma.

It is much less spread in endobronchial surgery $[7,9]$ and practically not used in the treatment of metastatic lesion of pleura.

The use of the method of radio-frequency ablation in the treatment of the central lung cancer as well as at the secondary pleurisy is a new direction in the palliative treatment of lung cancer and its complications. Among these complications must be named the tumor stenosis of trachea and bronchi, metastatic pleurisy. The use of RFA at these complications improves the patients' life quality and prolongs their life.

Methods of VATS RFA of lung tumors at the open operations are the author's elaborations that are in the process of research. In the further after collecting the sufficient number of patients we plan to devote the separate article to these types of interventions.

Authors who used this method in the treatment of the primary and metastatic lung cancer noted the positive palliative effect [1-6]. The sphere of the use of this method is usually used by the peripheral lung tumors when the surgical intervention was impossible [2-6, 8, 10]. All aforesaid allowed share the primary experience of RFA use in the treatment of malignant tumors of lungs and pleura. 


\section{Aim of the work}

Analysis of the possibilities of the different methods of RFA of the lung and pleura tumors.

\section{Material and methods}

In hospital the different RFA methods were carried out in 186 patients: 75 men and 33 women 48-79 years old. Among the studied group of patients the primary lung cancer was in 145 cases.

By the morphological tumor structure 71 had the squamous cell cancer, 25 - small cell, 49 glandular one. Metastatic lung cancer was observed in 41 patients. Most patients were refused in the surgical treatment because of tumor spread 054 , because of the heavy concomitant pathology and age -25.32 ones were refused in chemoradiotherapy.

The high-frequency electrosurgical device for the volume coagulation of biological tissues ESHF-150 "FOTEK" with output power up to $80 \mathrm{~W}$ was used as an apparatus for RFA. Electrode EM-218 was used directly for the volume coagulation.

For endobronchial RFA was used endocardial electrode for cardioablation.

The types and used methods of RFA are presented in the Table $\mathbf{1 .}$

Table 1

Types of RFA methods in the treatment of lung and pleura tumors

\begin{tabular}{lc}
\hline \multicolumn{1}{c}{ RFA method } & Number of observation \\
\hline 1. Puncture transtoracic RFA & 61 \\
2. VATS RFA of tumor & 15 \\
3. RFA at transtoracic open interventions & 10 \\
4. Endobronchial RFA with recanalization of the tumor stenosis & 75 \\
5. RFA pleurodesis at metastatic pleurisy & 25
\end{tabular}

The method of transtoracic RFA is a transdermal insertion in the tumor of the aforesaid electrode using angiographic complex Allara Xper FD - 20 «Phillips». Operation was carried out from the side access under intravenous anesthesia without intubation of trachea. The X-ray control demonstrated the position of electrode in the tumor. In several cases electrode was put in the different parts of tumor. The parameters of the momentary RFA were: the output power of impact $60 \mathrm{~W}$, the time of exposition 40-60 seconds, and in several cases the thermal impact of air waves was repeated. After the end of RFA the X-ray control was carried out to excluding pneumothorax.

At RFA under VATS control was used the general anesthesia with exclusion of the operated lung from respiration. Operation was carried out from the side access with insertion of video-camera through the $10 \mathrm{~mm}$ thoracoport in V-VI intercostals spaces on the middle-back axillary lines. After visual assessment of lesion depending on localization of the peripheral tumor the electrode was transtoracically put in it. RFA was carried out under the visual control using the puncture of tumor from the different points. The parameters of impact did not differ from the aforesaid ones. Operation was finished by insertion of drainage and smoothing of the lung.

At the open method of RFA was used the standard side thoracotomy in V intercostals space. After the revision and assessment of the lesion volume the radio-frequency electrode was put in the tumor tissue from the different points. The RFA parameters corresponded to the aforesaid ones. The method of RFA and pleurodesis at metastatic pleurisy corresponded to the VATS one. But RFA was carried out on the parts of parietal pleura by the subpleural insertion of electrode. For these aims was used the elongate electrode that allows manipulate in the different parts of hemithorax. At presence of metastatic nodes on pleura RFA was carried out by putting electrode under their base, their diameter was $0,5-3,0 \mathrm{~cm}$.

Endobronchial RFA was carried out under the local anesthesia using fibrobronchoscopes «Olympys, Pentax». RFA was carried out by the contact between electrode and tumor. At the beginning was realized the destruction of the surface tumor layers then of its deeper parts, at this process was used the output power $30 \mathrm{~W}$ with the time of impact $20-40$ seconds. 3 operations were usually needed for the full RFA and renewal of patency. 


\section{Results of research}

RFA of the primary and metastatic tumors of lungs and pleura was realized when the radical surgical treatment was considered as impossible that is proved by the data of other authors $[2-6,8,10]$. In our series of observations the direct positive effect of RFA such as destruction of tumor at the use of puncture method was noticed in $87 \%$ of patients. Among 61 analyzed patients the survivability in terms up to 1 year $-84 \%$ of patients, to 2 years $-63 \%$ of patients, to 3 years $-49 \%$ of patients.

The most spread complication of this method is pneumothorax that is observed in $20 \%$ of patients $[4,8]$. The other complications of RFA are seldom and do not exceed $0,6 \%$ [4]. In our series of observations pneumothorax was observed in $13 \%$ of patients and easily eliminated by the drainage of pleural cavity during 1-2 days. The complications such as hemoptysis are very seldom. In our observation it was observed in $0,3 \%$ of patients.

RFA at the open operative interventions was used in 10 patients. This method was realized when at the operative intervention was revealed that elimination of tumor is impossible. For decrease of the tumor sizes it was ablated with the further chemotherapy of radiotherapy. On the control CT of the chest organs in 1 month after RFA the tumor sizes decreased in 2-3 times. Then the special treatment was realized.

We carried out RFA of trachea and bronchi in 75 patients with the tumor stenosis of respiratory tract as a palliative measure. The local anesthesia allows use it even in patients with severe respiratory insufficiency. The use of RFA and recanalization is considered as possible at exophytic form of endobronchial tumor with preservation of the anatomic reference points as the bronchial wall and partially preserved bronchi clearance. Peribronchial bronchi compression makes this method useless and even dangerous.

The existing numerous methods of pleurodesis at metastatic exudative pleurisy indicate the absence of the unified effective methodology of treatment. The elaborated method of VATS RFA of parietal pleura for creation of pleurodesis was used in 25 patients with metastatic exudative pleurisy. At the same time exists the possibility of elimination of the large metastases on parietal pleura $0,5-3 \mathrm{~cm}$.

In the result the direct positive effect, the stop of exudation, was attained in $91 \%$ of patients. In terms of observation up to 1 year the relapse of pleurisy was observed in 2 patients. It is worth noting, that realization of this method of pleurodesis was successfully underwent by this heavy category of patients. Any complications in the early postoperative period were not observed. The mean terms f drainage of the pleural cavity were 2-3 days and the patient's stay in hospital 4-5 days. The elaborated method of pleurodesis is rather simple but assessment of its effectiveness needs further collection of the clinic material.

Radio-frequency ablation in combination with VATS was carried out in 15 patients. The positive result as a destruction of tumor was attained in y $100 \%$ of patients, the complication as hemoptysis was observed in 1 patient. On the control CT in 5 month after RFA the relapse of tumor was not observed.

\section{Discussion of the results of research}

According to S. Jain and co-authors (5) RFA allows essentially add the other methods of conservative treatment of tumors despite its palliative character. Although, according to T. Scheider and co-authors [8] the full necrosis of tumor after RFA is observed in 37,5\% of cases, this method must not replace the radical operations if possible. The main method of RFA of lung tumors is puncture transtoracic way carried out under the control of computed tomography $[2-6,10]$. The own experience demonstrated the possibility to use x-ray angiographic set for such purposes. At the same time the permanent X-ray control on the position of electrode in tumor allows carry out RFA from the different points. In addition after the end of RFA appears a possibility to detect the probable pneumothorax and make the timely drainage of pleural cavity.

Like other authors $[5-6,8]$ we observed the primary appearance of edema and infiltration in the RFA zone with the further decrease of lesion zone, corrugation and scarring of the wound tumor. In several cases can take place the transformation of the tumor tissue into pseudocyst [9]. The 
direct effectiveness of RFA of the lung tumors is rather high, thus, A. Baisi and co-authors [2] noted the positive effect of RFA in $95 \%$ of patients with the peripheral tumor less than $5 \mathrm{~cm}$ and at $3 \mathrm{~cm}$ tumor the 5 -years survivability reached $50 \%$ that is proved by the other authors [4]. O. N. Kachanov and S. V. Kozlov [1] did not reveal any difference in treatment after the comparative analysis of survivability after RFA and atypical resection of metastases of squamous cell cancer. But the progressing of the tumor process after RFA was noticed in $23 \%$ of patients [4]. The significant advantages of puncture RFA is an objective control on the tumor destruction, low cost price with satisfactory frequency of complication and lethality [5, 18-20].

RFA under the VATS control has some advantages; visual control on RFA makes an intervention significantly different and allows the maximal impact of high-frequency waves on tumor. Unfortunately the realization of these methods needs endotracheal and one-lung anesthesia that is not always possible in elderly patients with expressed concomitant pathology. The direct positive effect of RFA was attained in all patients. Such complication as hemoptysis was observed in 1 patients and was treated conservatively. Combination of two methods allowed carry out RFA pleurodesis on parietal pleura in patients with small metastases (1-2 mm. This type of pleurodesis is more effective than the earlier known [12-17] because it allows carry out metastasectomy.

The method of RFA at open operative interventions is also the author's one. The positive effect as the decrease of tumor was attained in $100 \%$ of cases. The defect of this method is an impossibility to control the process of ablation and assess the results of RFA during the operation.

At the same time with an impact on the tumor can be carried out RFA of the lymph nodes of mediastinum.

There are no contradictions to this operative intervention. Any complications were not observed during the operation and postoperative period.

The experience of use of endobronchial RFA of tumor is essentially limited [7,9]. Thus, T. Tanabe and co-authors [9] used this method at treatment of the central forms of lung cancer of I stage. The impact was realized using the special electrode with its internal cooling with liquid under the control of computed tomography. The further surgical treatment with morphological examination demonstrated that this method can be used as an independent one when the operative treatment is impossible. Taking into account that we mainly used this method in patients with I-IV stages of lung cancer, it is difficult to compare our results because it is not described for this category of patients by any author. After RFA the patients' life quality and the parameter of external respiratory function improved. The single complication was hemoptysis that appeared in 2 patients in our research and was eliminated by medicaments.

\section{Conclusions}

So, the collected primary experience of RFA of pleura and lung tumors allows make the following conclusions:

1. RFA can be the method of choice in treatment of the peripheral cancerous tumors and lung metastases in cases when surgical treatment is considered as impossible.

2. The main method of RFA of such tumors can be the transtoracic puncture under x-ray control.

3. The use of RFA of tumors at open and VATS operations needs the further study.

4. The methods of endobronchial RFA and creation of pleurodesis need the further collection of clinical experience and objective assessment.

\section{References}

[1] Kaganov, O. I., Kozlov, S. V. (2011). Copmparative analysis of short-term and long-term effects of radiofrequency thermoablation and atypical lung resection in treatment of metastatic colorectal cancer. Sibirskij onkologicheskij zhurnal, 6, 19-22.

[2] Baisi, A., De Simone, M., Raveglia, F., Cioffi, U. (2012). Thermal ablation in the treatment of lung cancer: present and future. European Journal of Cardio-Thoracic Surgery, 43 (4), 683-686. doi: 10.1093/ejcts/ezs558

[3] Fernando, H. C. (2012). Editorial Comment: The present and future of thermal ablation for lung cancer. European Journal of Cardio-Thoracic Surgery, 43 (4), 687-687. doi: 10.1093/ejcts/ezs612 
[4] Huang, L., Han, Y., Zhao, J., Wang, X., Cheng, Q., Li, X. et. al (2011). Is radiofrequency thermal ablation a safe and effective procedure in the treatment of pulmonary malignancies? European Journal of Cardio-Thoracic Surgery, 39 (3), 348-351. doi: 10.1016/j.ejcts.2010.06.004

[5] Jain, S. K., Dupuy, D. E. (2005). Radiofrequency Ablation for Thoracic Neoplasms. Tumor Ablation, 353-368. doi: 10.1007/0-387-28674-8_29

[6] Johnson, B. E., Jänne, P. A. (2005). Tumor Ablation for Patients with Lung Cancer: The Thoracic Oncologist's Perspective. Tumor Ablation, 459-465. doi: 10.1007/0-387-28674-8_38

[7] Marasso, A., Bernardi, V., Gai, R., Gallo, E., Massaglia, G. M., Onoscuri, M., Cardaci, S. B. (1998). Radiofrequency resection of bronchial tumours in combination with cryotherapy: evaluation of a new technique. Thorax, 53 (2), 106-109. doi: 10.1136/thx.53.2.106

[8] Schneider, T., Reuss, D., Warth, A., Schnabel, P. A., von Deimling, A., Herth, F. J. F. et. al (2011). The efficacy of bipolar and multipolar radiofrequency ablation of lung neoplasms - results of an ablate and resect study. European Journal of Cardio-Thoracic Surgery, 39 (6), 968-973. doi: 10.1016/j.ejcts.2010.08.055

[9] Tanabe, T., Koizumi, T., Tsushima, K., Ito, M., Kanda, S., Kobayashi, T. et. al (2010). Comparative Study of Three Different Catheters for CT Imaging-Bronchoscopy-Guided Radiofrequency Ablation as a Potential and Novel Interventional Therapy for Lung Cancer. Chest, 137 (4), 890-897. doi: 10.1378/ chest.09-1065

[10] Thanos, L., Mylona, S., Pomoni, M., Athanassiadi, K., Theakos, N., Zoganas, L., Batakis, N. (2006). Percutaneous radiofrequency thermal ablation of primary and metastatic lung tumors. European Journal of Cardio-Thoracic Surgery, 30 (5), 797-800. doi: 10.1016/j.ejcts.2006.08.015

[11] Roberts, M. E., Neville, E., Berrisford, R. G., Antunes, G., Ali, N. J. (2010). Management of a malignant pleural effusion: British Thoracic Society pleural disease guideline 2010. Thorax, 65, ii32-ii40. doi: 10.1136/thx.2010.136994

[12] Meuris, K., Hertoghs, M., Lauwers, P., Hendriks, J. M., Van Schil, P. E. (2012). Subtotal pleurectomy by video-assisted thoracic surgery for metastatic pleuritis. Multimedia Manual of Cardio-Thoracic Surgery, 2012 (0), mms008-mms008. doi: 10.1093/mmcts/mms008

[13] Srour, N., Amjadi, K., Forster, A. J., Aaron, S. D. (2013). Management of Malignant Pleural Effusions with Indwelling Pleural Catheters or Talc Pleurodesis. Canadian Respiratory Journal, 20 (2), 106-110. doi: $10.1155 / 2013 / 842768$

[14] Shaw, P. H., Agarwal, R. (2013). Pleurodesis for malignant pleural effusions. Reviews. doi: 10.1002/14651858.cd002916.pub3

[15] Schulze, M., Boehle, A. S., Kurdow, R., Dohrmann, P., Henne-Bruns, D. (2001). Effective treatment of malignant pleural effusion by minimal invasive thoracic surgery: thoracoscopic talc pleurodesis and pleuroperitoneal shunts in 101 patients. The Annals of Thoracic Surgery, 71 (6), 1809-1812. doi: 10.1016/ s0003-4975(01)02586-3

[16] Hooper, C. E., Elvers, K. T., Welsh, G. I., Millar, A. B., Maskell, N. A. (2012). VEGF and sVEGFR-1 in malignant pleural effusions: Association with survival and pleurodesis outcomes. Lung Cancer, 77 (2), 443-449. doi: 10.1016/j.lungcan.2012.03.006

[17] Korolev, D. G., Skupchenko, A. V., Skobel'cov, D. A., Lysenko, A. V., Koroleva, O. L. (2010). Radiochastotnaja abljacija u bol'nyh s periferi cheskim rakom legkogo. Vysokie tehnologii v medicine, 1-2.

[18] Koroleva, O. L., Suhinina, E. M., Skupchenko, A. V., Korolev, D. G. (2010). Ocenka rezul'tatov radiochastotnoj abljacii zlokachestvennyh novoobrazovanij legkih. Vysokie tehnologii v medicine, 1-2.

[19] Granov, A. M., Davydov, M. I. (Eds.) (2013). Intervencionnaja radiologija v onkologii. SanktPeterburg: OOO “Foliant”, 560. 